\title{
An Analysis of the Determinants of Education Quality in Malawi: Pupil Reading Scores
}

\author{
S.H. Dunga \\ Lecturer at University of Malawi, Chancellor College; \\ PhD Candidate at North-West University; \\ Email: stevedunga@gmail.com
}

Doi: 10.5901/mjss.2013.v4n4p337

\begin{abstract}
The study investigated the factors that affect primary education quality in Malawi. Data from SACMEQ II on reading scores for Malawi was regressed in ordinary least squares. A basic multilevel analysis was also conducted to account for the variation at school level and student level. The results show that pupil gender, socio-economic status, speaking English at home, class size had a positive impact on reading scores. Moreover, the age of the student, absenteeism, having class in the open, teachers' years of teaching were negatively associated with pupil reading scores. This mean that policies aimed at improving quality should be focused not only on the school resources but also on mitigating student level challenges.
\end{abstract}

Key Words: Reading scores. Multilevel Analysis, Pupil, SACMEQ

\section{Introduction}

The effort on increasing the percentage of enrolment in primary schools has been the focus of most developing countries since the JomtienConference of 1990. A number of countries have over the last two decades introduced free primary education to deal with the need to increase their enrolments. However the effort to increase enrolment has been met with a challenge of quality. Lately research on basic education has focused on the quality aspect of the mass education being offered in the schools (Chimombo, 2005).Policies aimed atachievingbasic literacy and numeracy have been proposed both on the global and national fronts. International organisations and financial institutions have committed themselves to funding efforts that help to achieve universal basic education by 2015 under the Millennium Development Goals (MDGs). Organisations like the World Bank and United Nations have set out policies specifically on education in developing countries. Emphasis is put on basic literacy and numeracy because commentators of returns to education (Glewwe \& Jacoby, 1994; Psacharopoulos G. , 1994) have found out that returns are higher for basic or primary education in developing countries.

Malawi is one of the countries that have put basic education in the fore front. In 1994 the country scrapped off tuition fees in primary schools and the following year enrolment double (Al-Samarri \& Zaman, 2007). Studies done in the field of basic education have revealed thatmany pupils are still leaving school without mastering a minimum set of cognitive and non-cognitive skills(Chimombo, 2005). Also the teaching staffs in many low-income countries do not meet the minimum standards of the teaching profession(UNESCO, 2011). Overcrowded classes, poorly qualified teachers and ill-equipped schools with scant or completely no learning materials remain a common scenario in many developing countries, Yet achieving education for all fundamentally relies on assuring decent and quality education. It becomes pertinent therefore to establish the main challenges and the factors that affect quality of basic education. Also attempt to identify the required policy directions around the challenge of quality so that there is no trade-off between quality and quantity in the process. This paper is therefore set to analyse the factors that determine the quality of basic education both on student and school level.

The rest of the paper is organised as follows; section two reviews the literature on education quality putting emphasis on the measurements, section three presents the methodology used, stipulating the data used and the method of analysis. results and discussions will be subsections of section three. Section four present the conclusion of the paper.

\section{Literature Review}

Generally, there are two dimensions to the approach of education quality. The first dimension is championed by economists working in the field of education who look at quality of education in terms of inputs. This school of thought 
defines quality of education as the amount and quality of resources invested in schools or schooling. Tan et al (1997)in their study in the Philippines found out that, classroom furniture and workbooks, provide the highest payoff in terms of school achievement in the first grade while Glewwe and Jacoby (1994) also found that classroom quality (measured by blackboards and non-leaky roofs) is more important than teacher training in determining student achievement in Ghana (Glewwe and Jacoby 1994). This approach by economists looks at inputs as education quality or school quality together with other factors such as teacher quality, teacher remuneration, and class size as affecting student outcomes, and the better quality of the inputs the higher or preferable the output (Hanushek 1994; Hedges, Laine et al. 1994; Suryadarma, et al. 2006). The controversy within the economist's definition relates to what output they focus on. For example Card and Kruger (1992) and Betts (1995) in measuring the impact of school quality on subsequent wages presented contrasting results but measured school quality at different levels by looking at stage averages versus individual school level.

Educationists on the other hand, define education or school quality in terms of the outcomes of the education process. A widely used measure in this interpretation is student achievement measured by test scores. In developed countries where most schools have the necessary facilities, education quality is often defined in terms of school effectiveness. This is basically how schools differ in their performance, controlling for student prior attainment also called between school variance. The performance is measured using scores as well. In most countries schools are ranked according to how students perform after controlling for student characteristics like parents education, social economic status of the family and resources at home. The focus however is mainly on how resources which are assumed available are utilised in the teaching and learning process. A good measure of school effectiveness is the one that controls for all other factors that the school does not influence. In examining school effectiveness, Goldstein (1997) indicated that it is used to describe educational research concerned with exploring differences within and between schools. But in capturing education quality, it involves choosing an outcome, such as examination achievement and studying the average differences among the schools in question. This is a concern in developed countries where to a larger extent adequate school resources are available to all schools.

In developing countries educational quality is looked at in terms of results and how they are affected by the inputs. Just as in developed countries, the difference in schools is a concern. However, most schools equally lack resources and the focus is not how the available resources are used but how the availability of resources affects the scores, given that student background factors are controlled for in order to capture the school effect. It is therefore the educationists' interpretation that is used in the school effectiveness research and output is a quality measure. This approach of educationists will be adopted in this paper. Student outcomes will provide the measure of quality of education, which is modelled as determined by a host of factors.

\section{Methodology}

The study uses multilevel analysis where an empty model and a model with both student and school level variables are estimated. The empty model is used to determine the percentage of variation attributable to student level factors and school level factors. Section there will present the empty model in more detail.

\subsection{Data}

The study reported here is based on data from Southern and Eastern Africa Consortium for Monitoring Educational Quality $\left(\mathrm{SACMEQ}^{1}\right)$ policy research project II. These data are collected on all the participating countries in Southern Africa. Malawi has participated in both the SACMEQ I and SACMEQ II. Both these rounds of research were designed to provide an assessment of the conditions of schooling and the quality of education provided by primary education systems in the participating countries. These two projects gathered overlapping data at different time points 1995 for SACMEQ I and 2000 for SACMEQ II.Data collection for Malawi was finished in December 2002. Using data for Malawi on the test scores for grade sixpupils, this studyattempts to explore the factors that affect student test scores which are used here as a measure of quality.

${ }^{1}$ SACMEQ is a body of ministers of education from fifteen African countries set to monitor basic education quality among other things. SACMEQ came into effect in 1995 when the ministers of education for these countries formalised their collaboration. The countries include; Botswana, Kenya, Lesotho, Malawi, Mauritius, Mozambique, Namibia, Seychelles, South Africa, Swaziland, Tanzania (Mainland), Tanzania (Zanzibar) Uganda Zambia and Zimbabwe 


\subsection{Regression Models}

The paper estimates the model with the reading scores as a dependent variable. The basic model is as follows;

$$
Q=\beta_{0}+\beta_{1} \text { ZPSER }+\beta_{2} \text { ZSRTOT22 }+\beta_{3} \text { ZXQPROF }+\beta_{4} \text { ZSLOC }+\beta_{5} \text { ZSPTRATI }+\varepsilon
$$

$Q$ = is the pupil score, $\beta_{0}$ : is the coefficient notation for intercepts for the whole model, $\beta_{1, \ldots .}$ are coefficients for the independent variables, ZPSES - is a measure of student background. It is a derived variable in the SACMEQ II most used variables category. It is a measure of a pupil's social economic status (SES). It is measured on a range of 1 to 15 , created out of home possessions, parents' education, lighting, floor, wall and roof of the house,ZSRTOT22 - is a derived variable for total school resources for SACMEQ II. It has a maximum of 22 items, corresponding to the number of resource items that were commonly used,ZXQPROF - this is a variable for the teacher qualification. It's a dummy of 1 for and 0 for those without a teaching qualification, ZSLOC dummy for school location. Isolated and rural areas were combined from the rural category and small town and large city classification were combined for the urban category so as to produce a 0/1 dummy variable. Table 3.5 shows the distribution as of the schools by locality, ZSPTRATI- is the pupil teacher ratio for SACMEC II. It is the total number of pupils divided by the total number of teachers.

\subsection{Empty Model}

An empty model is the simplest form and the starting point of a multilevel model. The rationale behind an empty model is to locate the variation in the dependent variable between the levels to be considered. In this study the empty model allocates the variation between pupil level (level 1) and school level (level 2) before the effects of the independent variables are accounted for. The independent variables included in the regressions in this study are assumed fixed. These include the factors that are considered to have an effect on the quality of education in Malawi.

$$
\begin{aligned}
& Q_{i j}=\beta_{0 j}+e_{i j w h e r e ;} \\
& \beta_{0 j}=\mu_{00}+u_{0 j} \text { hence; } \\
& Q_{i j}=\mu_{00}+u_{0 j}+e_{i j}
\end{aligned}
$$

Where $\mu_{00}$ is the population grand mean, uojis the specific random effect of school $\mathrm{j}$ andeijis the residual effects from pupil $i$ in the school. The levels are from pupil to school level. There is no class level because there was only one class that represented the whole school in the survey. Therefore the micro unit is the pupil and the macro unit is the school. This means thatthe school $j$ has a true mean of $\beta_{0 j}$ which is $\mu_{00}+u_{0 j a n d}$ each pupil within the school $j$ has a score that

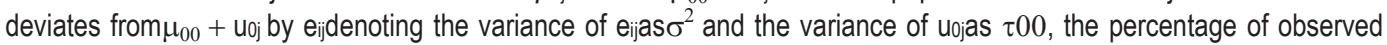
variation in the dependent variable attributable to school-level characteristics is found by dividing $\tau 00$ by the total variance $\sigma^{2}+\tau 00$ (Albright, 2007)

$$
\rho=\tau 00 /\left[\sigma^{2}+\tau 00\right]
$$

The ratio in equation (5) which is basically $\rho$, is the intra-class correlation coefficient(s). The percentage of variance which is attributable to pupil level traits is easily found as it is $1-\rho$ (Albright 2007). When the empty model reveals significant variance due to the school level variable, then the school variables can be added to equation (2) of the intercept term. In this case it is expected that there is an impact at school level due to school location where those in the urban area are expected to score higher than the ones in the rural area. The teacher qualificationis also likely to be different between those in the urban schools and in the rural area schools. Hence the teacher qualification can be added to the intercept equation (3) as well. This produces the following equation:

$$
\beta_{0 j}=\mu_{00}+\mu_{01}\left(\text { ZSLOC }_{j}\right)+\mu_{02}\left(\text { ZXQPROF }_{j}\right)+u_{0 j}
$$

With the fixed effect of pupil back ground measured at pupil level and an interaction between school location and pupil background, the whole equation will be as follows;

$$
\begin{aligned}
& Q_{i j}=\mu_{00}+\beta_{1}(Z S L O C j)+\beta_{2}\left(Z_{X Q P R O F}\right)+\beta_{3}\left(\text { ZPSES }_{i j}\right)+\beta_{4}\left(\text { ZPSES }_{i j} * Z S L O C_{j}\right) \\
& +\beta_{5}(\text { ZPSES })+u_{j} e_{i j}
\end{aligned}
$$


The model is extended by the inclusion of the school facility variable, parental education, pupil teacher ratio, pupil gender, as well as a host of pupil level characteristics like gender age, absenteeism among others.

\section{Findings and Discussion}

\subsection{Descriptive statistics of the important variables}

The total number of pupils in the study Malawi sampled was 2333. The representation in the sample had 1220 boys making up 52.3 percent and 1113 girls amounting to 47.7 per cent of the sample. The dependent variable, pupil's score, is a continuous variable that was standardised to have a mean of 500 and a standard deviation of 100 . The mean for the pupil reading score was 423 below the standardised mean of 500.70 per cent of the schools were categorised as being located in the rural area and 30 per cent were in town or city. Of the sample, 58.1 percent of the sample indicated that they never speak English at home, whilst 31.9 percent indicated 'sometimes' and 2.8 percent 'often'. The 'sometimes' and 'often' responses were put together and hence the 'speak English' dummy had two categories.

\subsection{Factors affecting student performance}

In dealing with the objective of the paper which is essentially, what are the factors that affect quality of primary education? The results in Table 3 above have the school level variables that affect pupil's performance. The pupil characteristics found to be statistically significant in affecting performance whether positively or negatively include, student age, pupil gender, pupils social economic status, how many times the pupil was absent, whether they speak English at home and whether they have books at home or not. These variables are statistically significant in all regressions. This shows the impact of pupil characteristics in the test scores.

Table 3: Regression results

\begin{tabular}{|l|c|c|c|c|}
\hline & \multicolumn{2}{|c|}{ Regression $1^{2}$} & \multicolumn{2}{c|}{${\text { Regression } 2^{3}}$} \\
\hline & Beta & $\mathrm{p}$-value & Beta & $\mathrm{p}$-value \\
\hline Constant & 470.80 & $.000^{* *}$ & 432.2 & $.000^{* *}$ \\
\hline Age in Months & -.121 & $.000^{* *}$ & -.107 & $.000^{* *}$ \\
\hline Pupil Gender & .078 & $.000^{* *}$ & .078 & $.000^{* *}$ \\
\hline Pupil SES & .181 & $.000^{* *}$ & .115 & $.000^{* *}$ \\
\hline Days pupil was absent & -.045 & $.022^{* *}$ & -.056 & $.004^{* *}$ \\
\hline Speak English at home & .195 & $.000^{* *}$ & .174 & $.000^{* *}$ \\
\hline Have books at home & .068 & $.001^{* *}$ & .071 & $.000^{* *}$ \\
\hline Total school resources & & & .076 & $.001^{* *}$ \\
\hline Have class in open & & & -.093 & $.000^{* *}$ \\
\hline Teachers gender male 1 & & & -.013 & .609 \\
\hline Teachers years of teaching & & & -.092 & $.000^{* *}$ \\
\hline Grade 6 class size & & & .0118 & $.004^{* *}$ \\
\hline Teacher reading score & & & -.058 & $.003^{* *}$ \\
\hline Pupil teacher Ratio & & & -.035 & .100 \\
\hline
\end{tabular}

** significant at 95\% confidence interval *significant at 90\% confidence interval

A constant of 470.80 for regression 1 and 432.2 for regression 2 imply that without considering the effect of all the other factors, the constant is what a pupil would score on average. Days absent and age have a negative effect on the pupil score. On days absent, it is common sense that a pupil that does not attend class is likely to fail. On age, the reason may be that of over age. Most pupils in Malawi especially in the rural area schools are over the age expected for the class they are in. One of the reasons is due to multiple enrolments where pupils drop out and come back later. The other reason is late enrolment where pupil enrolment at ages of 8,9 even 10 years and they feel over age and hence demotivated. It is also likely to reflect home background. Wealthier parents and those keener on education are more likely to start their child at the right age. Malawi gross enrolment is much higher and net enrolment is lower signifying the fact that there are more pupils in classes below their age group.

${ }^{2}$ Regression 1 has Pupil reading score regressed by pupil characteristics

${ }^{3}$ Regression 2 has Pupil reading scores regressed by both pupil and school characteristics 
The dummy of whether the pupil speaks English at home is the highest in its effect. However this is a binary variable with those speaking English at home scoring .195 more standard deviations of the mean score. An increase in a score of Social Economic Status (SES) increases the standardised score by .181 and .165 standard deviations. This might not be a very big effect but big enough to impact on student score.

After the pupil level factors are controlled for, regressions two and four shows how the school level variables affect the pupil reading score. With a mean of 432.2 represented by the constant, the pupil is expected to score the value of the constant when all other factors are equal to zero. On the standardised coefficient level, class size and school resources have the most effect of .118 standard deviations regression two. As pointed out in the motivation of the study, most schools in Malawi do not have the basic resources that are required for teaching and learning process. Although the impact indicated by the standardised coefficient is small, it is still statistically significant and it signifies the importance of school resources in the performance of pupils. With more resources provided to primary school, there is evidence that pupil performance can improve.

The policy of free primary education is blamed to have resulted in massive increases in enrolment; however, the effect of class size in regression two is positive implying that, big classes perform better than smaller classes. However this may be due to the fact that most of the big classes reported in the data are found in towns and cities where population is high. And since most resources are in towns and good students from better SES are found in towns, there may be an endogeniety problem resulting from better pupils going to big well-resourced schools, or the other possible source of higher scores in big classes is due to the fact that good students from better family are attracted by well performing schools hence leading to big class sizes. And hence big class size reporting higher scores, may not necessarily be because of the size but because of the student composition.

Learning in the open and teacher years of teaching experience have negative effects. Learning outside can lead to cancellation of classes in the rainy season, and pupils get distracted by not being confined in class. This is the case in most schools in Malawi very few if any schools have enough classrooms for all the classes at the school. Hence those leaning in the open, score -0.093 standard deviations for regressions two. Teacher experience may also represent age of the teachers. Research (Filmer 1999) has shown that teachers improve in the first five years of their careers; afterwards, they relax and sometimes deteriorate in their performance. Therefore the results in Table 3 indicate that a marginal change in the years of teaching has a -0.092 effect standard deviations on the pupil standardised score.

The dependent variable used is the standardised pupil reading scores. Regression one has only the student level characteristics as explanatory variables and regression two have both student factors and school factors.

\section{Conclusion}

The paper has discussed the factors that affect primary education quality which was proxied by pupil's reading scores as collected by SACMEQ II. The results indicate that both pupil level and school level factors have a significant effect on how students perform. Policies that are aimed at improving pupil performance need to focus on school resources, like building more classes to avoid having classes in the open. There is also need to introduce monitoringmechanisms to control teacher's laxity as indicated by the negative effect of teacher's years of teaching.

\section{References}

Al-Samarri, S., \& Zaman, a. H. (2007). Abolishing School fees in Malawi: The impact on education access and equity. Education Economics, 15(3), 359-376.

Chimombo, J. P. (2005). Quantity versus quality in education: Case studies in Malawi. International Review of Education(55), $155-172$.

Dunga, S. (2012). Determinants of Quality Basic education in developing countries; factors that mater. NY: Lambert Academic Publishing.

Filmer, D. (2010). Retrieved 03 13, 2012, from http://econ.worldbank.org: http://econ.worldbank.org/projects/edattain

Glewwe, P., \& Jacoby, H. (1994). Student Achievement and schooling choice in low income countries. Journal of Development Studies(32), 554-584.

GoM. (2008). Education sector Implementation Plan 2009-217. Lilongwe: Malawi Governemnt.

Hanushek, E. (1994). Money might matter Somewhere: A response to the Hedges, laine and greenwald. Educational research, 23, 5-8.

Hedges, L., Laine, R., \& Greenwald. (1994). Does Money Matter: A Meta-analysis of studies of the effect of differential school inputs on students outcome. Educational research, 23, 5-14.

Monk, D. (1990). Education Finance: an economic Approach. New York: McGrawHill.

Psacharopoulos, G. (1985). Education for Development. Washington: Oxford University Press.

Psacharopoulos, G. (1994). Returns too investment in Education: A global update. World Development, 9, 1325-1343. 
Tan, J. J., \& Coustere, L. C. (1997). Putting inputs to work in Elementary Schools: What can be done in the Philippines. Economic Development and Cultural Cahnge(45), 857-879.

UNDP. (2008). Malawi Poverty Report.

UNESCO. (2011). Financing Education in Sub-Saharan Africa | Meeting the Challenges of Expansion, Equity and Quality. Montrea: UNESCO Institute for Statistics.

WorldBank. (2010). The Education system in Malawi; Country Status Report. Washington, D.C: Library of Congress Cataloging in Publication Data

\section{Reference to the Web}

Albright, J. J. (2007). Estimating Multilevel Models using SPSS, Stata, and SAS. http://www.indiana.edu/ statmath/stat/all/hlm/h/m.pdf 